\title{
САРКОПЕНИЯ ОБЗОР ЛИТЕРАТУРЫ И РЕЗУЛЬТАТЫ СОБСТВЕННЫХ ИССЛЕДОВАНИЙ
}

В шестом из этих действий Является он тощим паячем, С очками на носу и с сумкой сбоку; Штаны его, что юношей еще Себе он сшил, отлично сохранились, Но широки безмерно для его Иссохших ног

\author{
The sixth age shifts \\ Into the lean and slipper \\ With spectacles on nose and pouch on side, \\ His youthful hose well sav'd, a world too wide \\ For his shrunk shank
}

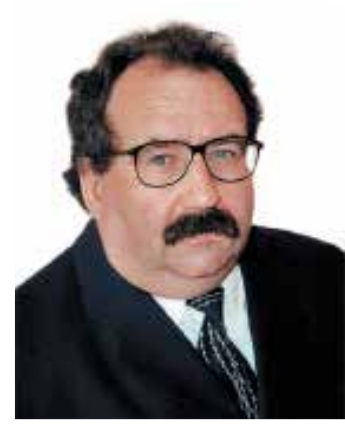

В.В. ПОВОРОЗНЮК, д.мед.н., профессор, руководитель отдела клинической физиологии и патологии опорнодвигательного аппарата ГУ «Институт геронтологии им. Д.Ф. Чеботарева НАМН Украины»

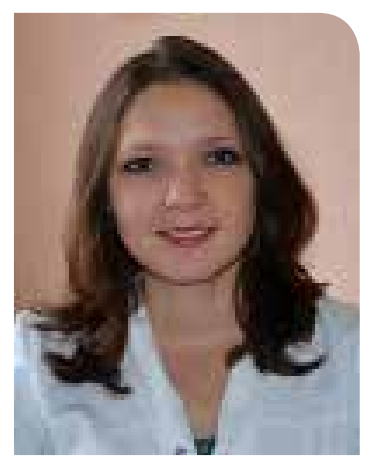

Н.И. ДЗЕРОВИЧ, к.мед.н., старший научный сотрудник отдела клинической физиологии и патологии опорнодвигательного аппарата гУ «Институт геронтологии им. Д.Ф. Чеботарева НАМН Украины»
Capkr аркопения - атрофическое дегенеративное изменение скелетной мускулатуры, ассоциированное с возрастом и приводящее к постепенной потере мышечной массы и ее силы.

До недавнего времени саркопения не привлекала должного внимания геронтологов и других специалистов. Роль состояния скелетной мускулатуры, ее массы и силы в сохранении здоровья и увеличении продолжительности жизни оставалась недооцененной, но в последние 15 лет отношение специалистов к этому вопросу изменилось. По данным американского центра контроля заболеваемости (Center for Disease Control and Prevention, CDC), саркопения признана одним из пяти основных факторов риска заболеваемости и смертности у лиц в возрасте старше 65 лет $[3,6,10]$.

Саркопения не входит в действующую международную номенклатуру и классификацию болезней, но ее включение планируется в следующее издание международной классификации болезней.

Впервые изменения мышечной ткани с возрастом были описаны Гиппократом, но только в 1989 г. Irwin Rozenberg для описания потери массы скелетной мускулатуры с возрастом предложил использовать термин «саркопения» (от греч. sarx - тело, плоть + penia - снижение). В 1998 г. Richard Baumgartner описал саркопению как синдром, ассоциированный с повышенным риском падений и физической слабостью.

На сегодняшний день термин «саркопения» используется для описания возрастных изменений в скелетной мускулатуре (возрастная саркопения), что отражает не только снижение общей мышечной массы, но и сопутствующее снижение мышечной силы и мышечной функции [6].

\section{ЭПИДЕМИОЛОГИЯ}

Саркопения наблюдается как у мужчин, так и у женщин. В исследовании NHAMES (National
Health and Nutrition Examination Survey) частота саркопении у населения Нью-Мексико составила среди мужчин 15\%, среди женщин $24 \%$. У лиц старше 80 лет данный показатель составил более 50\%. У жителей Великобритании европеоидной расы саркопения встречалась в 53\% случаев у мужчин, 31\% - у женщин. Меньшая частота саркопении наблюдалась у женщин Дании старше 70 лет - 12\%, а также у женщин и мужчин старше 80 лет, проживающих в Тайване, - $19 \%$ и $26 \%$, соответственно. Среди американцев старше 80 лет 50\% мужчин и $72 \%$ женщин страдают саркопенией, а саркопения II степени наблюдалась, соответственно, у 7\% и $11 \%$ из них. Установлено, что саркопения чаще встречается у латиноамериканского населения [6, 20].

Термин «саркопения» обычно не используют для описания потери мышечной массы при вторичных состояниях (острых и подострых катаболических процессах: сепсисе, ВИЧ-инфекции, кахексии при раковых заболеваниях, послеоперационных состояниях, голодании, тяжелой почечной недостаточности, хронических обструктивных заболеваниях легких).

В ряде исследований установлено, что саркопения ассоциирована с повышением риска падений, снижением минеральной плотности костной ткани, ухудшением качества жизни, функциональных возможностей и, соответственно, ростом летальности пациентов с данным состоянием [6].

\section{ПРИЧИНЫ САРКОПЕНИИ}

Существует много причин, приводящих к потере мышечной массы. Чаще всего саркопения наблюдается у людей пожилого возраста. Выделяют первичную и вторичную форму саркопении. Первичная форма развивается с возрастом при отсутствии влияния различных вторичных факторов на скелетную мышечную ткань. Вторичная форма саркопении является следствием воздействия одного или 


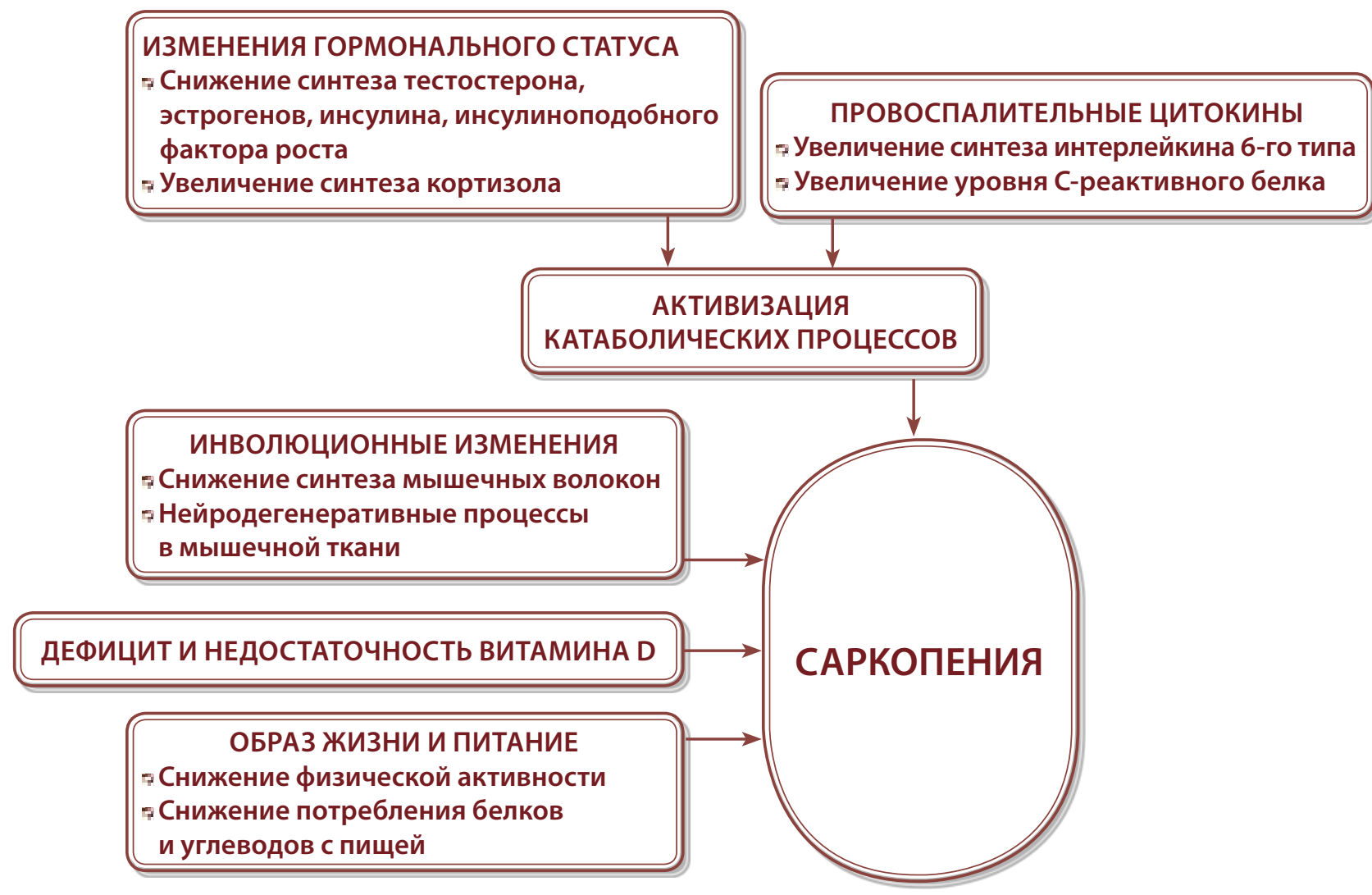

нескольких состояний/факторов, оказывающих влияние на состояние мышечной ткани (саркопения, ассоциированная со сниженной физической активностью, с питанием, сопутствующей патологией и др.). У большинства лиц пожилого возраста природа саркопении мультифакторная (рис. 1).

В последнее время особое внимание специалисты уделяют изучению нейромышечных синапсов как ключевой структуры в осуществлении функциональной денервации, которая ведет к потере мышечной массы и мышечной слабости [14].

В ряде исследований подтверждена роль возрастзависимого увеличения оксидативного стресса в развитии нейромышечной дегенерации и прогрессировании саркопении $[11,14]$

\section{Телостроение человека:}

роль жировой и тощей массы

Жировая ткань в норме составляет 15-20\% массы тела у мужчин и 20-25\% у женщин. Жировая ткань в организме необходима для функционирования жизненно важных органов и систем: костного мозга, внутренних органов, мышц и центральной нервной системы. Аккумулирование жировой ткани наблюдается в подкожной жировой клетчатке и вокруг внутренних органов. Минимальный ее уровень в организме человека, необходимый для функционирования органов и систем, у женщин составляет $8 \%$, у мужчин - $5 \%$.
Обезжиренная или тощая ткань в организме человека представлена мышечной тканью, связками, кожей и компонентами сосудистой системы. Около 40\% массы тела человека составляют скелетные мышцы и приблизительно 10\% приходится на долю гладких мышц и мышцы сердца. Пик мышечной массы у мужчин и женщин приходится на 25 лет, к 50 годам наблюдается потеря $10 \%$ мышечной массы, к 80 годам - 30\%. Средняя потеря мышечной массы у человека составляет $1 \%$ в год после 35-40 лет [3].

\section{Оценка тощей массы}

Для оценки потери мышечной массы с возрастом Richard Baumgartner et al. (1998) предложили использовать индекс тощей массы (ИТМ), при расчете которого учитывается тощая масса верхних и нижних конечностей. В тощую массу туловища входят также паренхиматозные органы. При оценке же тощей массы конечностей оценивается скелетная мускулатура, кожа, связки и сосудистая система:

ИТМ = тощая масса верхних и нижних конечностей $\left(\kappa r / p o c т\left(m^{2}\right)\right)$.

Диагноз саркопении устанавливают при снижении ИТМ на два стандартных отклонения (SD) по сравнению с практически здоровыми молодыми людьми соответственно полу. Крайняя точка ИТМ, установленная

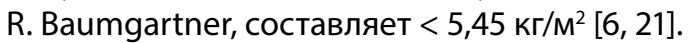

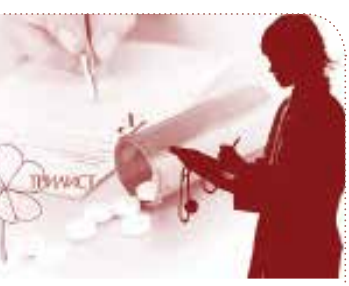

Для оценки потери мышечной массы с возрастом R. Baumgartner et al. (1998) предложили использовать индекс тощей массы (ИТМ) = тощая масса верхних и нижних конечностей $($ кг/рост²). Крайняя точка ИТМ составляет $<5,45 \mathrm{kr} / \mathrm{M}^{2}$ 


\begin{tabular}{|c|c|c|c|c|}
\hline ТАБЛИЦА 1 & \multicolumn{3}{|c|}{} \\
\hline Стадии & Мышечная масса & Мышечная сила & & Мышечная функция \\
\hline Пресаркопения & $\downarrow$ & & & \\
\hline Саркопения & $\downarrow$ & $\downarrow$ & Или & $\downarrow$ \\
\hline Тяжелая саркопения & $\downarrow$ & $\downarrow$ & & $\downarrow$ \\
\hline
\end{tabular}

ТАБЛИЦА 1.

СТАДИИ САРКОПЕНИИ

(EWGSOP, 2009)

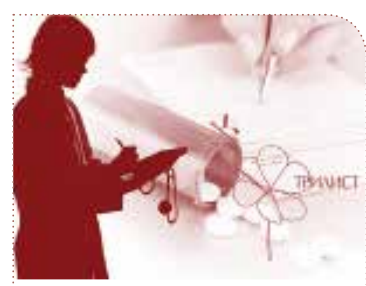

Диагностические критерии саркопении (EWGSOP, 2009):

7 снижение мышечной массы; 7 снижение мышечной силы; 7 снижение мышечной функции

Тем не менее, на сегодняшний день термин «саркопения» широко не используется в клинической практике. В связи с этим Европейское общество гериатрической медицины (European Union Geriatric Medicine Society, EUGMS) в 2009 г. создало Рабочую группу по изучению саркопении (European Working Group on Sarcopenia in Older People, EWGSOP), целью работы которой является разработка дефиниций и диагностических критериев саркопении, используемых в клинической практике и при проведении клинических исследований [8]. Члены других Европейских сообществ - European Society of Clinical Nutrition and Metabolism (ESPEN), International Academy of Nutrition and Aging (IANA), International Association of Gerontology, Geriatrics-European Region (IAGG-ER) - также были приглашены в Рабочую группу по изучению саркопении. На первых заседаниях EWGSOP, которые были проведены в 2009 г., рассматривались следующие вопросы:

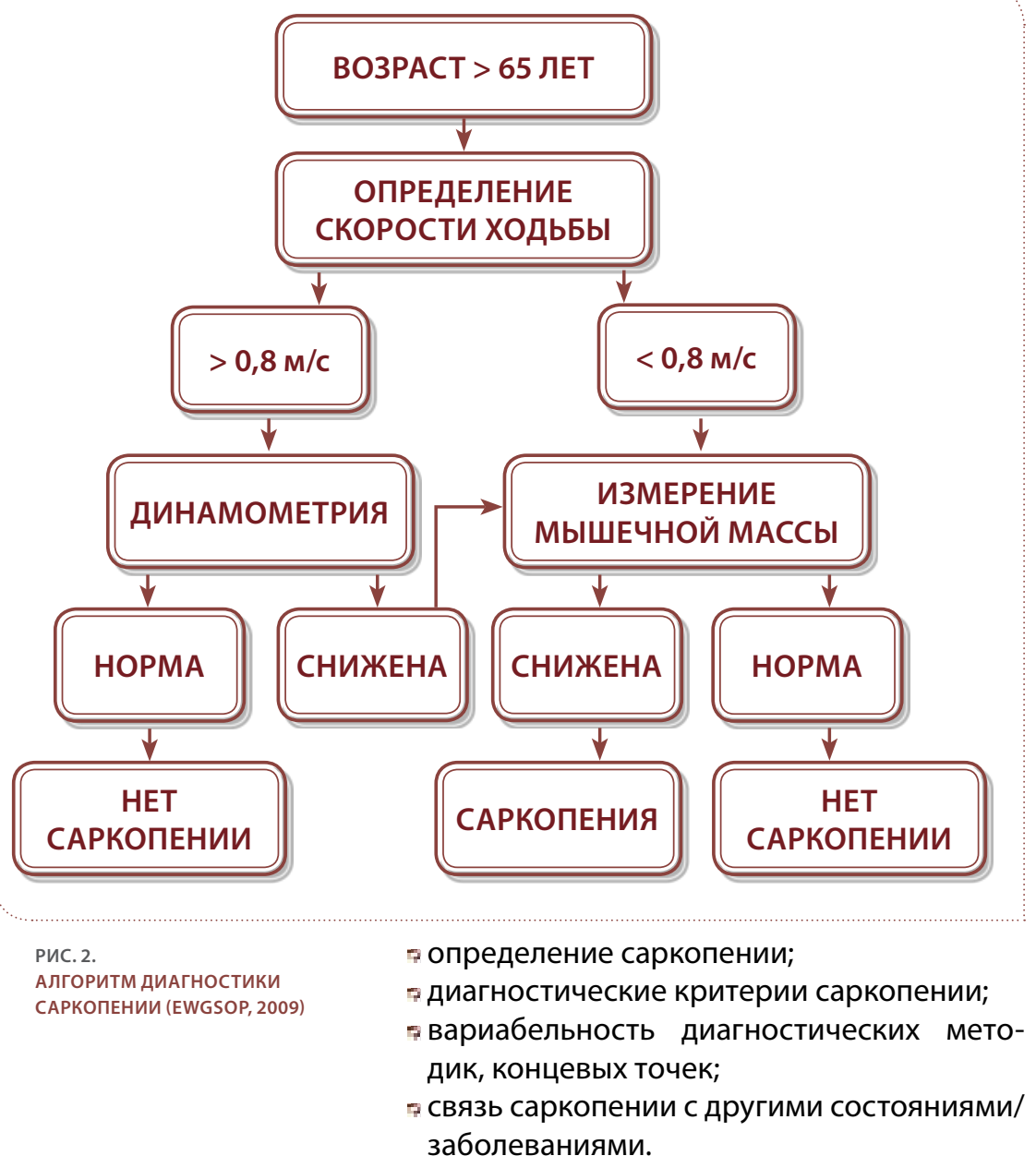

B результате работы пяти сообществ (EWGSOP, EUGMS, ESPEN, IAGG-ER, IANA) был создан консенсус по диагностике саркопении.

Саркопения - синдром, который характеризуется прогрессивным и генерализированным снижением скелетной мышечной массы и ее силы с риском развития таких осложнений, как нарушение подвижности, снижение качества жизни и смерть (EWGSOP, 2009).

\section{Диагностика и признаки саркопении}

Для постановки диагноза «саркопения» необходимо определение не только скелетной мышечной массы, но и ее силы и функциональных возможностей, так как сила мышечной массы не зависит исключительно от ее массы и взаимосвязь между данными показателями не является линейной.

Диагностические критерии саркопении (EWGSOP, 2009):

1) снижение мышечной массы;

2) снижение мышечной силы;

3) снижение мышечной функции.

Постановка диагноза саркопении основывается на выявлении двух из трех вышеперечисленных критериев. Наличие первого критерия является обязательным.

Стадийность развития саркопении отображает тяжесть состояния. Рабочая группа EWGSOP выделила три стадии развития саркопении (табл. 1):

? I - пресаркопения, характеризуется снижением мышечной массы без снижения ее силы и функции;

7II - саркопения, характеризуется снижением скелетной мышечной массы, ее силы или функции;

- III - тяжелая форма саркопении, характеризуется снижением всех трех параметров (мышечной массы, ее силы и функции).

Группой EWGSOP предложен алгоритм диагностики саркопении (рис. 2). При использовании данного алгоритма необходимо учитывать коморбидные состояния, индивидуальные особенности пациентов. У лиц моложе 65 лет применение алгоритма возможно при наличии факторов риска.

На сегодняшний день для оценки скелетной мышечной массы, ее силы и функции существует широкий спектр методик (табл. 2). Стоимость, доступность и простота в использовании определяют их применение в клинической практике и при проведении клинических исследований.

Для оценки жировой и обезжиренной массы используют КТ, МРТ и двухфотонную рентгеновскую абсорбциометрию (ДРА). КТ и МРТ являются стандартом диагностики физиологических и патологических состояний мягких тканей и часто используются в клинических 


\begin{tabular}{|c|c|c|}
\hline Показатель & $\begin{array}{c}\text { Методы, используемые } \\
\text { в клинических исследованиях }\end{array}$ & $\begin{array}{l}\text { Методы, используемые } \\
\text { в клинической практике }\end{array}$ \\
\hline \multirow[t]{6}{*}{ Масса скелетной мускулатуры } & KT & Биоимпедансный анализ \\
\hline & MPT & \multirow[t]{5}{*}{ Двухфотонная рентгеновская абсорбциометрия } \\
\hline & Двухфотонная рентгеновская абсорбциометрия & \\
\hline & Биоимпедансный анализ & \\
\hline & $\begin{array}{c}\text { Тотальное или частичное определение калия в обе- } \\
\text { зжиренных мягких тканях }\end{array}$ & \\
\hline & Антропометрия & \\
\hline \multirow[t]{3}{*}{ Сила скелетной мускулатуры } & Динамометрия & \multirow[t]{3}{*}{ Динамометрия } \\
\hline & Оценка сгибания/разгибания коленного сустава & \\
\hline & Пиковая скорость выдоха & \\
\hline \multirow[t]{4}{*}{ Функциональные возможности мышечной ткани } & Tect SPPB (Short Physical Performance Battery) & Tect SPPB \\
\hline & Тест на определение скорости ходьбы & Тест на определение скорости ходьбы \\
\hline & Тест «подъем по лестнице» & \multirow[t]{2}{*}{ Тест «подъем по лестнице» } \\
\hline & Тест «подняться и пройти» & \\
\hline
\end{tabular}

исследованиях. В рутинной практике определение жировой ткани с помощью КТ и МРТ ограничено в связи с высокой стоимостью обследования и повышенным уровнем ионизирующего излучения. В данном случае ДРА выступает альтернативой для определения жировой и обезжиренной ткани как в клинических исследованиях, так и в практике. Диагностической погрешностью использования ДРА в определении саркопении является невозможность разделить подкожную и висцеральную жировую ткань, а также то, что в состав обезжиренной ткани входят и паренхиматозные органы. Обезжиренная масса конечностей наиболее точно совпадает с их мышечной массой. Поэтому в клинических исследованиях по изучению саркопении учитывают не только общий показатель обезжиренной массы, но и выделяют сумму показателей обезжиренной массы верхних и нижних конечностей - аппендикулярную массу скелетной мускулатуры. Техническая ошибка при измерении процентного содержания жировой массы и аппендикулярной массы скелетной мускулатуры с помощью ДРА составляет $\pm 1,5 \%$ и $\pm 3,0 \%$, соответственно. При проведении ДРА лучевая нагрузка минимальна (0,037 милиБЭР (Биологический Эквивалент Рентгена), 0,01 милиГрей) по сравнению с другими методиками. Различия же в информативности ДРА и КТ, МРТ составляют менее $5 \%[5,7,15,23]$.

Более 10 лет для оценки жировой и обезжиренной ткани в практике применяют простой в использовании, недорогой и воспроизводимый метод - биоимпедансный анализ. Формулы разработаны для различных этнических групп, установлены референтные данные для мужчин и женщин различного возраста европеоидной расы. Поэтому биоимпедансный анализ является хорошей портативной альтернативной методикой ДРА.

Оценку жировой массы можно проводить также с использованием УзИ. Измеряют подкожную, преперитонеальную и висцеральную жировую ткань в верхней трети живота по срединной линии (от мечевидного отростка до пупка), устанавливая перпендикулярно линейный датчик (частота 7,5 МГц).

Тотальное или частичное определение уровня калия в обезжиренных мягких тканях - классическая методика диагностики состояния скелетной мышечной ткани, так как в ней содержится более $50 \%$ калия всего организма. Но в рутинной клинической практике данный метод используется редко.

При проведении клинических исследований в оценке особенностей телостроения активно продолжают использовать антропометрию - наиболее портативный, универсальный, недорогой и неинвазивный метод. Обычно измеряют окружность верхнесредней трети плеча и толщину складки. Размер окружности плеча положительно коррелирует с массой мышечной ткани, размер < 31 см ассоциирован с нетрудоспособностью. Известно, что возрастзависимые изменения жировой ткани и потеря эластичности кожи с возрастом увеличивают ошибку измерений у лиц пожилого возраста. Для оценки степени ожирения используют индекс массы тела, предложенный ВОЗ в 1995 г., а также определяют окружность живота, бедер и их соотношение [5].

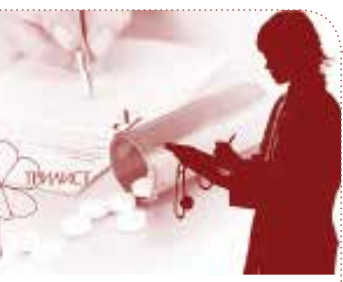

Стадии развития саркопении:

? I- пресаркопения, характери-

зуется снижением мышечной массы без снижения ее силы и функции;

? II - саркопения, характеризуется снижением скелетной мышечной массы, ее силы или функции;

? III - тяжелая форма саркопении, характеризуется снижением мышечной массы, ее силы и функции 
ТАБЛИЦА 3

\begin{tabular}{|c|c|c|c|c|c|}
\hline Возрастная группа, лет & $\mathbf{n}$ & Возраст, лет & Poct, $\mathrm{M}$ & Macca, кг & $\begin{array}{c}\text { Индекс массы тела, } \\
\text { кг/M² }\end{array}$ \\
\hline $20-24$ & 143 & $22,27 \pm 0,11$ & $1,66 \pm 0,010$ & $57,87 \pm 0,85$ & $21,03 \pm 0,30$ \\
\hline $25-29$ & 209 & $26,99 \pm 0,10$ & $1,66 \pm 0,010$ & $58,98 \pm 0,79$ & $21,49 \pm 0,26$ \\
\hline $30-34$ & 271 & $32,03 \pm 0,09$ & $1,66 \pm 0,003$ & $62,23 \pm 0,70$ & $22,65 \pm 0,24$ \\
\hline $35-39$ & 326 & $37,00 \pm 0,08$ & $1,66 \pm 0,003$ & $66,12 \pm 0,74$ & $24,12 \pm 0,26$ \\
\hline $40-44$ & 419 & $42,17 \pm 0,07$ & $1,65 \pm 0,003$ & $70,17 \pm 0,70$ & $25,78 \pm 0,24$ \\
\hline $45-49$ & 794 & $47,26 \pm 0,05$ & $1,64 \pm 0,002$ & $72,90 \pm 0,54$ & $27,11 \pm 0,19$ \\
\hline $50-54$ & 1292 & $52,10 \pm 0,04$ & $1,63 \pm 0,002$ & $75,08 \pm 0,40$ & $28,14 \pm 0,15$ \\
\hline $55-59$ & 1534 & $57,01 \pm 0,04$ & $1,63 \pm 0,001$ & $77,51 \pm 0,37$ & $29,30 \pm 0,14$ \\
\hline $60-64$ & 1193 & $61,81 \pm 0,04$ & $1,62 \pm 0,002$ & $77,18 \pm 0,41$ & $29,32 \pm 0,15$ \\
\hline $65-69$ & 943 & $67,08 \pm 0,05$ & $1,61 \pm 0,002$ & $75,34 \pm 0,46$ & $29,19 \pm 0,17$ \\
\hline $70-74$ & 877 & $71,76 \pm 0,05$ & $1,60 \pm 0,002$ & $73,48 \pm 0,44$ & $28,87 \pm 0,17$ \\
\hline $75-79$ & 384 & $76,78 \pm 0,07$ & $1,59 \pm 0,003$ & $73,26 \pm 0,65$ & $29,01 \pm 0,24$ \\
\hline $80-84$ & 204 & $81,50 \pm 0,09$ & $1,59 \pm 0,004$ & $69,53 \pm 0,83$ & $27,54 \pm 0,29$ \\
\hline $85-89$ & 48 & $86,31 \pm 0,19$ & $1,57 \pm 0,010$ & $63,67 \pm 1,46$ & $25,96 \pm 0,50$ \\
\hline Всего & 8637 & $56,70 \pm 0,14$ & $1,62 \pm 0,07$ & $73,53 \pm 0,16$ & $27,90 \pm 0,10$ \\
\hline
\end{tabular}

АНТРОПОМЕТРИЧЕСКИЕ

ХАРАКТЕРИСТИКИ

ОБСЛЕДОВАННЫХ ПАЦИЕНТОК $(\mathrm{M} \pm \mathrm{M})$
ТАБЛИЦА 3.

\section{РЕЗУЛЬТАТЫ СОБСТВЕННЫХ ИССЛЕДОВАНИЙ}

На базе Украинского научно-медицинского центра проблем остеопороза (руководитель проф. В.В. Поворознюк) проведен анализ особенностей телостроения женщин различного возраста.

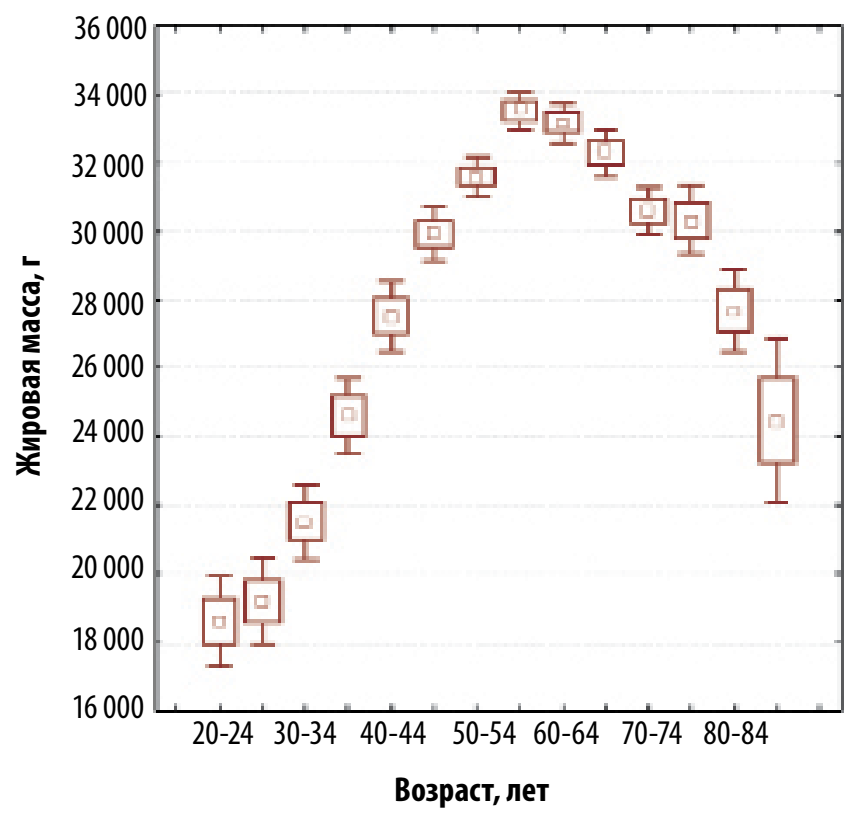

РИС. 3 А.

ПОКАЗАТЕЛЬ ЖИРОВОЙ МАССЫ (Г) У ЖЕНЩИН В ЗАВИСИМОСТИ ОТ BOЗРАCTA
A

Обследовано 8637 женщин в возрасте 20-89 лет. Их антропометрические характеристики представлены в табл. 3.

Показатели жировой и тощей массы оценивали с применением ДРА. Статистический анализ проводили с использованием программы «Statistica 6.0». Применяли корреляционный, регрессионный и однофакторный дисперсионный анализ.
В результате исследования был установлен пик накопления жировой и обезжиренной массы у женщин возрастной группы 50-59 лет (рис. 3). Полученные данные подтверждают гипотезу о равномерном накоплении и снижении у женщин показателей жировой и обезжиренной массы с возрастом. У мужчин во временном аспекте вначале наблюдается снижение мышечной массы с последующим повышением и поздним снижением жировой массы.

На рис. 4 и 5 представлены гистограммы распределения женщин в возрасте 65 лет и старше в зависимости от ИТМ и корреляционная связь между ИТМ и возрастом.

Частота саркопении у обследуемых пациенток в возрасте 65 лет и старше составила 7\%, при исключении женщин с ожирением - 10\%. В табл. 4 представлена частота саркопении в каждой возрастной группе. Данный показатель в возрастной группе 85-89 лет был достоверно выше $(p<0,005)$ по сравнению с другими группами.

Наше исследование на данный момент продолжается.

\section{ПРОФИЛАКТИКА И ЛЕЧЕНИЕ САРКОПЕНИИ}

\section{Занятия лечебной физкультурой}

Основным направлением в ведении пациентов с саркопенией являются физические нагрузки. Традиционно используют аэробные упражнения, которые полезны для улучшения состояния сердечно-сосудистой и дыхательной систем и оказывают положительное влияние на соотношение жировой и тощей массы тела. 
Известно, что силовые анаэробные физические нагрузки оказывают более значительное воздействие на костно-мышечную систему, предотвращая остеопороз и саркопению. Цикл занятий (курс составляет 10-12 нед., длительность занятий - 30 мин., частота - 2 раза в неделю) значительно увеличивает мышечную силу у пожилых мужчин и женщин. Эффективность физических нагрузок превышает результаты других видов лечения саркопении, применявшихся без сочетания с физической нагрузкой (различные варианты заместительной гормональной терапии, коррекция питания и др.) [6].

\section{Коррекция питания}

Известно, что количество потребляемой пищи у лиц пожилого возраста уменьшается - развивается возрастная анорексия вследствие влияния висцеральных, гормональных неврологических, фармакологических и психосоциальных факторов. В исследовании Sayhoun N. (1992) отмечено, что более 50\% лиц пожилого возраста употребляет менее 1,0 г высококачественного белка на 1 кг массы тела в день. Результаты исследования R. Roubenoff и V. Hughes (2000) показали, что 30\% лиц пожилого возраста употребляют менее 0,8 г/кг/сут. белка, 15\% - менее 0,6 г/кг/сут. Употребление белка в количестве менее 0,45 г/кг/сут. приводит к прогрессивной и быстрой потере тощей массы и снижению функционального состояния мышечной ткани. В исследовании S. Solerte (2008) установлено, что дополнительное назначение пациентам с саркопенией белка в дозе 0,25 г/кг/сут. вызывало достоверное повышение тощей массы. Оптимальным количеством белка для лиц пожилого возраста является 1,2-1,5 г/кг/сут., в то время как для человека средних лет - 0,8 г/кг/сут. Предварительные результаты недавно опубликованного рандомизированного исследования показали, что оптимальным количеством высококачественного белка является 25-30 г за один прием пищи, так как более высокое содержание белка не вызывает стимуляцию синтеза белков мышечной ткани $[6,20,25]$.

\section{Фармакотерапия}

Во многочисленных работах подтверждено увеличение риска развития саркопении (в 2 раза) при дефиците витамина D (менее 25 нмоль/л). Дополнительное назначение витамина D лицам пожилого возраста предупреждает развитие саркопении, нарушений функциональных возможностей и риск падений $[6,13,25]$.

В эпидемиологических исследованиях подтверждена взаимосвязь между снижением уровня тестостерона с возрастом и уменьше-

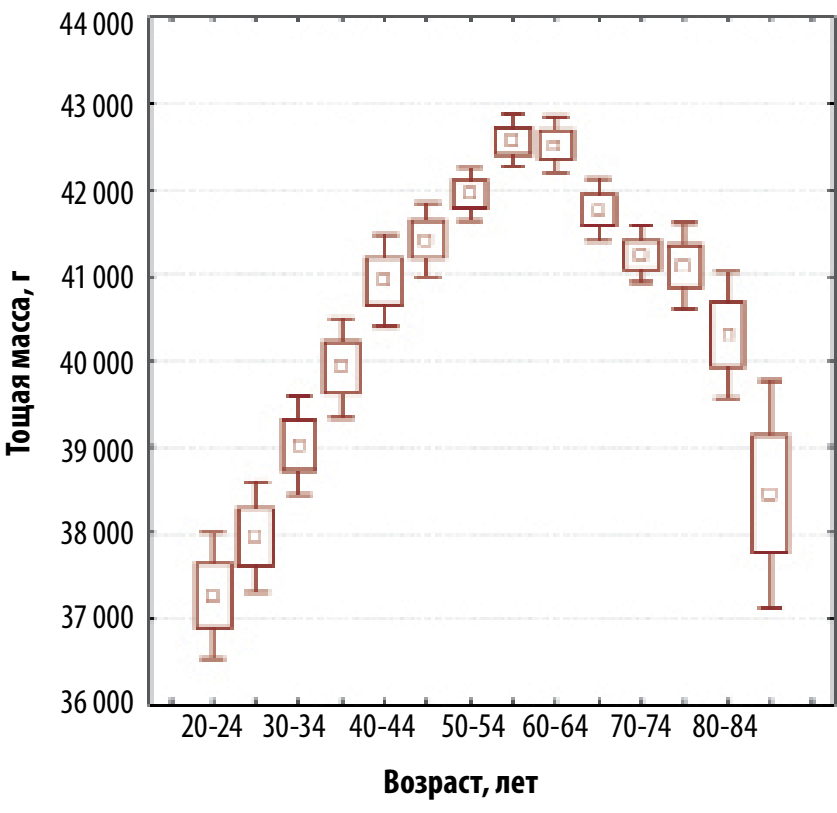

Б

нием мышечной силы и функции. Снижение уровня эстрогенов у женщин с возрастом, в период менопаузы также имеет значительное влияние на мышечную силу, так как известно, что эстрогены, конвертируясь в тестостерон, оказывают анаболический эффект на синтез мышечного белка. Кроме того, оба этих половых гормона угнетают продукцию провоспалительных цитокинов, оказывающих катаболическое влияние на состояние мышечной ткани. Однако назначение женщинам терапии препаратами, содержащими эстрогены

ПОКАЗАТЕЛЬ ТО У ЖЕНЩИН В ЗАВИСИМОСТИ ОТ BO3РACTA

\begin{tabular}{|c|c|c|c|}
\hline & \multicolumn{2}{|c|}{ ТАБЛИЦА 4 } \\
\hline Возрастная группа, лет & Вся группа, $\mathbf{n}$ & $\mathbf{n}$ & $\%$ \\
\hline $65-69$ & 943 & 72 & 7,6 \\
\hline $70-74$ & 877 & 54 & 6,1 \\
\hline $75-79$ & 384 & 24 & 6,3 \\
\hline $80-84$ & 204 & 14 & 6,9 \\
\hline $85-89$ & 48 & 5 & 10,4 \\
\hline Всего & 2456 & 169 & 6,8 \\
\hline
\end{tabular}

и тестостерон, существенно не повлияло на состояние мышечной силы. При назначении же заместительной терапии тестостероном мужчинам были получены противоречивые результаты в зависимости от возраста обследуемых. В нескольких исследованиях показана положительная роль терапии тестостероном на массу тощей ткани и мышечную силу у молодых гипогонадных мужчин. Мышечная сила у таких мужчин увеличивалась от 20 до $60 \%$ данные показатели были несколько ниже по сравнению с эффективностью силовых нагрузок. Анаболический эффект терапии тестостероном у гипогонадных мужчин пожилого 


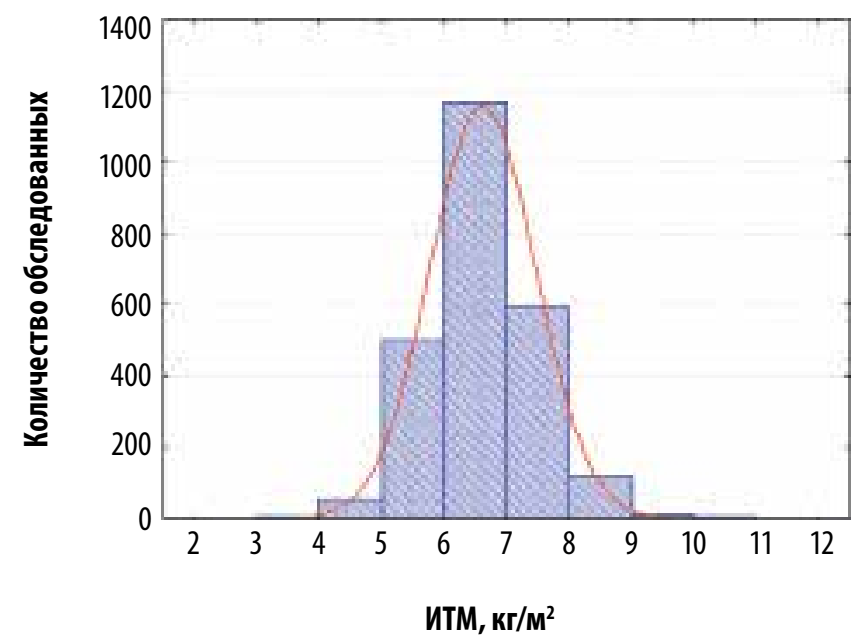

PИC. 4.

ГИСТОГРАММА РАСПРЕДЕЛЕНИЯ ОБСЛЕДОВАННЫХ ЖЕНЩИН В ВОЗРАСТЕ 65 ЛЕТ И СТАРШЕ В ЗАВИСИМОСТИ ОТ ИТМ возраста был менее выраженным: во многих исследованиях отмечены минимальные изменения в телостроении, увеличение мышечной силы не наблюдалось. Результаты ряда ис-

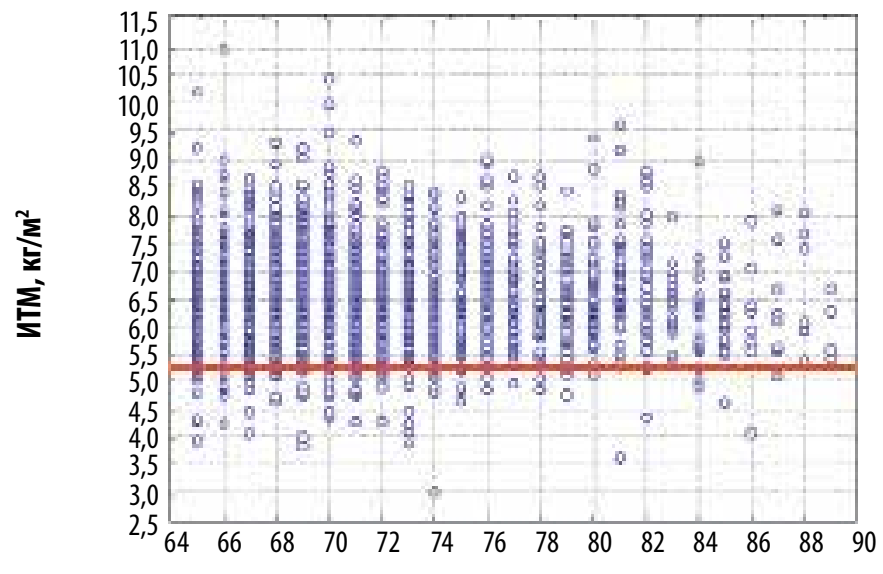

Возраст, лет

РИС. 5.

ИТМ У ОБСЛЕДОВАННЫХ ЖЕНЩИН В ЗАВИСИМОСТИ ОТ ВОЗРАСТА СОГЛАСHO R. BAUMGARTNER (1998): $\geq 5,45$ - HOPMA $,<5,45-$ САРКОПЕНИЯ следований показали увеличение мышечной силы от 10 до 25\%, но данные исследования не были плацебо контролируемыми. Также необходимо помнить, что назначение терапии тестостероном в небольших дозах у мужчин пожилого возраста может увеличивать риск развития рака предстательной железы [6, 7].

Интересные данные получены относительно влияния гомона роста на развитие саркопении. Гормон роста оказывает непрямое анаболическое влияние на мышечную ткань путем стимуляции продукции в печени инсулиноподобного фактора роста. Обычно уровень фактора роста у лиц пожилого возраста снижается. Поэтому существует гипотеза, что назначение терапии фактором роста у них может предупреждать потерю мышечной ткани. Тем не менее, результаты большинства исследований показали, что данная терапия неэффективна относительно состояния мышечной массы. Назначение рилизинг-гормона роста вызывало повышение уровня продукции гормона роста и умеренное повышение мышечной силы. В исследовании Boonen et al. выявлено, что при назначении непосредственно инсулиноподобного фактора роста женщинам пожилого возраста с недавно возникшим переломом шейки бедренной кости у них наблюдалось увеличение мышечной силы [6].

Перспективным направлением фармакотерапии саркопении на сегодняшний день является изучение эффективности и безопасности ингибиторов миостатина и селективных модуляторов андрогенных рецепторов [15].

Таким образом, саркопения определяется как гериатрический синдром, который часто наблюдается у лиц пожилого и старческого возраста, снижает их физические возможности, ухудшает качество жизни, способствует увеличению частоты падений и, соответственно, риска остеопоротических переломов. В связи с этим необходимы эпидемиологические исследования по изучению распространенности и факторов риска саркопении у лиц старших возрастных групп, разработка методов и средств диагностики, профилактики и лечения нарушений функционального состояния мышечной системы.

\section{ЛИТЕРАТУРА/REFERENCES}

\section{1. Поворознюк В.В.}

Захворювання кістково-м'язової системи в людей різного віку (вибрані лекції, огляди, статті). У 3 т. - К., 2009. - С. 664.

Povoroznyuk VV

Diseases of the musculoskeletal system in people of all ages (selected lectures, reviews, articles). 3 Vols. - K., 2009. - P. 664.

2. Поворознюк В.В., Григорьева Н.В.

Менопауза и костно-мышечная система. - К., 2004. - 512 с.

Povoroznyuk VV, Grigorieva NV

Menopause and musculoskeletal system. - K., 2004. - 512 p.

3. Ундрицов В.М., Ундрицова И.М., Серова Л.Д.

Саркопения - новая медицинская нозология // Физкультура в профилактике, лечении и реабилитации. - 2009. - 4 (31). - С. 7-16.
Undritsov VM, Undritsova IM, Serova LD

Sarcopenia as a new medical nosology // Physical training in prevention, treatment and rehabilitation. - 2009. - No. 4 (31). - P. 7-16.

4. Artur ST, Colley ID

The effect of physiological stimuli on sarcopenia; impact of notch and Wnt signaling on impaired aged skeletal muscle repair // International Journal of biological sciences. $-2012 .-8$ (5). $-731-760$.

5. Bonnik SL, Lewis LA

Bone densitometry for technologists // Humana Press Inc. - 2006. - $416 \mathrm{p}$.

6. Burton LA, Sumukadas D

Optimal management of sarcopenia // Clinical interventions in aging. - 2010. - 5. P. 217-228.

7. Campbell WW, Leidy HJ

Dietary protein and resistance training effects on muscle and body composition in older persons // Journal of the American College of Nutrition. - 2007. - 26 (6). - P. 696-703. 


\section{Chen Z, Wang Z, Lohman T et al.}

Dual-Energy $X$-ray absorptiometry is a valid tool for assessing skeletal muscle mass in older women // The journal of nutrition. - 2007. - 2775-2780.

9. Chumlea WmC, Cesari M, Evans WJ et al.

Sarcopenia: designing phase II B trials // J Nutr Health aging. - 2011. - 15 (6). P. 450-455.

10. Cruz-Jentoft AJ, Baeyens JP, Bauer JM et al.

Sarcopenia: European consensus on definition and diagnosis // Age and ageing. 2010. - 39. - P. 412-423.

11. Hall DT, Ma JF, Marco SD, Gallouzzi I

Inducible nitric oxide synthase (iNOS) in muscle wasting syndrome, sarcopenia and cachexia // Aging. - 2011. - 3. - P. 8.

12. Hong $\mathrm{S}$, Oh HJ, Choi H et al.

Characteristics of body fat, body fat percentage and other composition for Koreans from KNHANES IV - 2011. - 26. - P. 1599-1605.

13. Independent and combined effects of exercise and vitamin D on muscle morphology, function and falls in the elderly // Nutrients. - 2010. - 2. - P. 1015-1017. 14. Jang YC, Remmen HV

Age-associated alterations of neuromuscular junction // Exp Geront. - 2011. -

46 (2-3). - P. 193-198.

15. Lang T, Streeper T, Cawthon P et al.

Sarcopenia: etiology, clinical consequences, intervention and assessment //

0steoporos Int. - 2010. - 21. - P. 543-559.

16. Loeser RF

Age-related changes in the musculoskeletal system and the development of osteoarthritis // Clin Geriatr Med. - 2010. - 26 (3). - P. 371-386.

17. Mark DP, Sen A, Gordon PM

Influence of Resistance on lean body mass in aging adults: a meta-analysis // Med Sci Sports Exerc. - 2011. - 43 (2). - P. 249-258.
18. Marzetti E, Calvani R, Bernabei R, Leeuwenburgh C

Apoptosis in skeletal myocytes: a potential target for interventions against sarcopenia and physical frilty - a mini-review // Gerontology. - 2012. - 58. - P. 99-106.

19. Mayer F, Scharhag-Rosenberger F, Carlsohn A et al.

The intensity and effects of strength training in the elderly // Dtsch Arztebl Int. 2011. - 108 (21). - P. 359-64.

20. Mitchell WK, Williams J, Atherton P et al.

Sarcopenia, dynapenia and the impact of advancing age on human skeletal muscle size and strength; a quantitative review // Frontiers in physiology. 2012. - 3. - P. 260.

21. Neto LS, Karnikowiski MGO, Tavares AB, Lima RM association between sarcopenia, sarcopenic obesity, muscle strength and quality of life variables in elderly women // ISSN. - 2012. - P. 1413-3555.

22. Roberts HC, Denison H, Martin HJ et al.

A review of the measurement of grip strength in clinical and epidemiological studies: towards a standardized approach // Age and ageing. - 2011. - 40. - P. 423-429.

23. Park Y-W, Heymsfield SB, Gallagher D

Are dual-energy $X$-ray absorptiometry regional estimates associated with visceral adipose tissue mass? - 2002. - 26. - P. 978-983.

24. Travison TG, Araujo AB, Esche GG et al.

Lean Mass and Fat Mass is associated with male proximal femur strength // Journal of bone and mineral research. - 2008. - 23 (2). - P. 189-198.

25. Waters DL, Baumgartner RN, Garry PJ, Vellas B

Advantages of dietary, exercise-related and therapeutic interventions to prevent and treat sarcopenia in adult patients: an update // Clinical Interventions in aging 2010. - 5. - P. 259-270.

\section{САРКОПЕНІЯ: ОГЛЯД ЛІТЕРАТУРИ ТА РЕЗУЛЬТАТИ ВЛАСНИХ ДОСЛІДЖЕНЬ}

В.В. Поворознюк, д.мед.н., професор, керівник відділу клінічної фізіології та патології опорно-рухового апарату Інституту геронтології ім. Д.Ф. Чеботарьова НАМН України

\section{Н.І. Дзерович, Інститут геронтології ім. Д.Ф. Чеботарьова НАМН України}

Саркопенія є геріатричним синдромом, який часто спостерігається в осіб літнього та старечого віку, знижує їхні фізичні можливості, погіршує якість життя, сприяє збільшенню частоти падінь і, відповідно, ризику остеопоротичних переломів.

Для оцінки саркопенії (втрати м'язової маси) з віком використовують індекс знежиреної маси, а також такі дослідження, як КТ, МРТ і ДРА.

Профілактика і лікування саркопенії полягають у занятті лікувальною фізкультурою, корекції харчування і призначенні фармакотерапії.

Ключові слова: саркопенія, жирова тканина, індекс знежиреної маси.

\section{SARCOPENIA: LITERATURE REVIEW AND RESULTS OF OWN RESEARCH}

V.V. Povorozniuk, MD, professor, chief of the Clinical Physiology and Pathology of the Musculoskeletal System Department, Gerontology Institute named after D.F. Chebotarev NAMS of Ukraine

N.I. Dzerovych, Gerontology Institute named after D.F. Chebotarev NAMS of Ukraine

Sarcopenia is a geriatric syndrome that is often seen in elderly and senile patients. It reduces their physical abilities, affects the quality of life, increases the frequency of falls and consequently the risk of osteoporotic fractures.

Lean mass index and such studies as CT, MRT and DXA are used for sarcopenia diagnostic (loss of muscle mass with age).

Sarcopenia prevention and treatment are include exercise therapy, correction of nutrition and pharmacotherapy.

Keywords: sarcopenia, adipose tissue, lean mass index. 